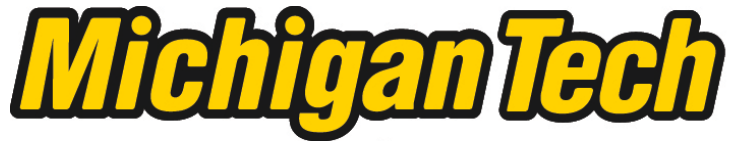 \\ Michigan Technological University Create the Future Digital Commons @ Michigan Tech
}

Dissertations, Master's Theses and Master's Reports - Open

Dissertations, Master's Theses and Master's

Reports

2014

\section{THE IMPACTS OF MITEP ON MY CAREER IN EDUCATION}

Kari A. Luckett

Michigan Technological University

Follow this and additional works at: https://digitalcommons.mtu.edu/etds

Part of the Science and Mathematics Education Commons

Copyright 2014 Kari A. Luckett

\section{Recommended Citation}

Luckett, Kari A., "THE IMPACTS OF MITEP ON MY CAREER IN EDUCATION", Master's report, Michigan Technological University, 2014.

https://doi.org/10.37099/mtu.dc.etds/880

Follow this and additional works at: https://digitalcommons.mtu.edu/etds

8 Part of the Science and Mathematics Education Commons 
THE IMPACTS OF MITEP ON MY CAREER IN EDUCATION

By

Kari A. Luckett

\begin{abstract}
A REPORT
Submitted in partial fulfillment of the requirements for the degree of MASTER OF SCIENCE

In Applied Science Education
\end{abstract}

MICHIGAN TECHNOLOGICAL UNIVERSITY

2014

(C) 2014 Kari A. Luckett 
This report has been approved in partial fulfillment of the requirements for the Degree of MASTER OF SCIENCE in Applied Science Education.

Department of Cognitive and Learning Sciences

$\begin{array}{cl}\text { Report Advisor: } & \text { Bradley Baltensperger } \\ \text { Committee Member: } & \text { Kedmon Hungwe } \\ \text { Committee Member: } & \text { Chris Wojick } \\ \text { Department Chair: } & \text { Susan L.Amato-Henderson }\end{array}$




\begin{abstract}
MiTEP, the Michigan Teacher Excellence Program, provides current teachers the opportunity to partner with Michigan Technological University to obtain graduate credit towards a Master's degree in applied science education. In exchange, the university collects data on the implementation of inquiry and earth science concepts into science classrooms. This paper documents my experience within this program, including how it has affected my personal and professional learning.
\end{abstract}


Introduction to Station Activities and Misconceptions in the Chemistry Classroom Research

\section{$\underline{\text { Report }}$}

In recent years, Michigan changed high school graduation requirements in science to three credits, including either Chemistry or Physics. Students with learning disabilities or students that struggle in Math are often pushed into Chemistry. Physics has more complex math concepts, whereas, Chemistry is more algebra-based. Algebra II, also a state graduation requirement, should have already been taken or should be taken concurrently to support the Math concepts found within Chemistry.

I teach at Kalamazoo Central High School in Kalamazoo, MI, and teach all of the cotaught Chemistry courses. This means I have the majority of students with IEPs, 504 plans, and English language learners because I have a special education support teacher within the class every day. I am always trying to provide my students with hands-on learning experiences; station activities afford students that opportunity. Stations also allow me to collect data about my students' progress, identify misconceptions and work with students in small groups.

I completed a group action research project with Claudia Witt and Rebecca Joyce, teachers in the MiTEP program. Together we selected stations and chemistry misconceptions as the focus of our research project. I was currently using stations and looking to expand, improve and collect data about the success of them in addressing misconceptions. Claudia Witt was also teaching the same Chemistry course at Loy Norrix High School in Kalamazoo, MI, and was interested in incorporating stations into her lesson plans. Throughout our research, my classroom was used for data collection and observation of the common misconception list we developed together. I collected data from student work (prior to, during, and after doing the stations activity) and then, together, we analyzed our findings. 
Chapter 1

Action Research: Station Activities and Misconceptions in the Chemistry Classroom

Claudia Witt, Kari Luckett, Rebecca Joyce

Kalamazoo Public Schools 


\section{Motivation for the study}

This action research was conducted by a group of three science teachers who have worked together as part of the Michigan Teacher Excellence Program (MITEP). The MITEP program was designed to develop teacher leaders who are empowered to "...lead their schools and districts through the process of systematically improving science teaching and learning." (Michigan Teacher Excellence) Though we each work in different high schools we have participated in this professional development program together for two years and share an interest in science education that is focused and effective for our students.

As part of our participation in MITEP, and in the Michigan Technological University Action Research course taught by Kedmon Hungwe, we collaborated on the design, implementation and reporting of an action research project. Our roles in the research reflect our current teaching roles. Claudia Witt has been teaching chemistry for six years at Loy Norrix High School in Kalamazoo Public Schools (KPS). Kari Luckett has been teaching chemistry at Kalamazoo Central High School in KPS for eight years. Rebecca Joyce works at the Kalamazoo Area Mathematics and Science Center, a county-wide program which supports math and science education. In the past she has taught high school physical science, earth science and elementary science. She currently works with high school students on college and career preparation. Claudia and Kari reflected on topics relevant to their needs in the classes they have in common. Rebecca, Claudia and Kari discussed the rationale for the research and decided on the research question. Rebecca researched publications addressing common misconceptions in chemistry and shared her summaries with Kari and Claudia as they planned their research design. In their respective classrooms, Claudia and Kari administered the learning stations, observed students, collected data, analyzed the misconceptions and chose samples of student work. Rebecca visited two of Claudia's classes to watch students working at learning stations and record observations. They 
worked together to draft and edit the report. Rebecca focused on the readings section, Claudia and Kari focused on descriptions of their classes and curricula, and together they discussed the analysis, interpretation and conclusions.

Kalamazoo Public Schools has two regular high schools and one alternative high school. Loy Norrix High School has 1514 students, 44\% of whom are white, 37\% African American, and 14\% Hispanic. Kalamazoo Central has approximately 1620 students, of whom 48\% are African American, 34\% are white, and 8\% are Hispanic. At Loy Norrix 66\% of students qualify for free and reduced lunch and at Kalamazoo Central 63\% of students qualify for free and reduced lunch.

Secondary schools in KPS have recently switched from a block schedule to trimesters, so what was once a one semester class of chemistry has been switched to a two trimester Chemistry A and Chemistry B class. A passing grade in Chemistry A is a prerequisite to be enrolled in Chemistry B. In Michigan, students must take either Chemistry or Physics to graduate (for KPS Chemistry A and Chemistry B or Physics A and Physics B). Most students choose to take Chemistry A and Chemistry B as there is a reputation for it being an easier, less math-intensive class. Claudia is part of one of the Sophomore Academy teams at Loy Norrix and most of her students are in 10th grade, although her students range from 10th to 12th grade. Kari is part of a liberal arts and international studies SLC, small learning community. The students in this SLC range from 10th to 12th grade. Based on her schedule, Kari primarily teaches outside of her SLC, having mainly 10th graders from the health and science and engineering small learning communities. There is no reading requirement for Chemistry in KPS, so readers of all abilities and levels can be enrolled. Students must pass both Biology A and B in order to enroll in Chemistry (or Physics). In addition, students must pass a minimum of Algebra in order to be eligible for Chemistry. As Chemistry/Physics is a graduation requirement, students who have previously been unsuccessful are re-enrolled in the class. Generally there are less than five "repeater" students in a given chemistry class. In KPS, we also give students the option of taking 
Honors Chemistry instead of General Chemistry. Honors Chemistry has a different curriculum, which covers the same content as General Chemistry, in addition to more complicated topics. KPS also offers sections of co-taught Chemistry, where a content teacher and a special education teacher teach together. These classes typically have between five and fifteen special education students in each class period. These students have a range of disabilities and receive services to have content modified and differentiated. At Kalamazoo Central, Kari teaches all of the co-taught chemistry classes.

In chemistry, many of the concepts require consistent and regular practice for students to master the concept. In co-taught classes, students were getting bogged down or overwhelmed by long and numerous worksheets. Also it was hard to see where students were developing misconceptions because the grading of many worksheets was cumbersome on the teacher. We wanted to find a way to practice the concepts in a segmented fashion, where students could address concepts in a small amount of time and with a limited number of questions and teachers could address small groups and look for/address misconceptions that had developed.

In both Claudia and Kari's Chemistry classes, all students are required to take a pretest at the beginning of the course. In addition, Claudia gives a five-question pretest at the beginning of each chapter. The questions chosen on the chapter pretest generally include broad topics to be covered within the chapter. Students are required to complete the pretests, and are given a formal grade on them which does not affect their overall class grade. The pretest grades are calculated with a weight of zero and are hidden in the online grade book so students and parents cannot see them. Comparing the class and chapter pretests to post tests in both situations help demonstrate student growth. Through the collaboration of Claudia and Kari, Claudia has started using station activities in her Chemistry classes. The hope is that with additional practice, more students show more success on their post tests (both chapter and final exam). The topic we chose to research dealt with the theory behind atomic structure. We picked this topic because our research was 
happening during the fall trimester and we had common content with Chemistry A during thattime. We wanted to give ourselves enough time to research and analyze our findings, so we determined the theory of atomic structure to be the ideal unit.

Claudia and Kari use daily warm ups which usually consist of a question for which there is a correct answer. After determining misconceptions using the pretests, they give a lecture with slides on the concept. Warm ups are used on subsequent days to help students review and explain in their own words corrections to these misconceptions. Warm ups are graded and returned to students on a daily basis. This year, stations have also been introduced to Claudia's classroom through collaboration with Kari, who uses them on a regular basis. During the stations activities, common misconceptions are addressed again and written about by the students. Students are invited to use notes, worksheets, books, warm ups, etc. during the stations activities, however they are encouraged to attempt to complete the activity without them to help them gauge their progress in a particular unit. Station activities are typically done the day prior to a test. To determine if the misconceptions were properly addressed and practiced, students were again assessed on their chapter test.

Since Kari and Claudia already have previous experience in using rotating learning stations and have found them worth continuing, we wanted to know more about this method and its effectiveness. We wanted to observe students more closely and gather data on their work in stations. We wanted to see if students stayed on task during station time and were able to complete the assignments at each station independently.

We also wanted to use the stations to address student misconceptions in chemistry. We often hear our students voice misconceptions when we elicit prior knowledge at the beginning of a unit. These conceptions can be difficult to change. We wanted to identify misconceptions students held in this unit, identify which students had these misconceptions, and help them develop their understanding. We hoped that we could more easily identify their misconceptions 
by observing students during the time they worked at stations and discussed station tasks with their peers. Other science teachers may be interested in the results of our study because the misconceptions we are investigating are common and may impact student understanding of chemistry, physics and biology.

\section{Research question}

The research question we chose was "What will happen if we try to use station activities to address student misconceptions in atomic structure?" Initially we planned to study the question "How will the use of station activities affect student misconceptions in the atomic structure unit?" However, when we planned our data collection design we decided "What will happen if we try to use station activities to address student misconceptions in atomic structure?" would be a more appropriate question because we were looking more generally at both teacher and student learning. We made this adjustment because we thought to answer the first question

thoroughly and conclude that the intervention of station activities affected student misconceptions we would need pre and post tests and a control group. We were not able to do that in this time period but it would be a good second stage for this action research.

\section{Readings about the study}

In our readings the terms "misconceptions," "pre-conceptions," and "student alternative conceptions" were used to describe ideas that were not in accord with current science. There is some controversy over these terms but we chose to use the term "misconception," judgmental as it is, because it reflects how these ideas are approached in our teaching practice. In an era of high 
stakes standardized testing we are motivated to teach students the "correct" and standard scientific explanations as quickly as possible.

We do, however, know that it is important for us to develop as much understanding as possible about what these misconceptions are. As Horton states, "Learning is an active process, and what students do with facts and ideas with which they have been presented depends to a very high degree on what they already think and believe. Being able to recognize and work with these student-held ideas and conceptions is thus a key component of an effective educational strategy." (Horton, 2004)

In some cases, the misconceptions are deeply rooted and make it hard for students to assimilate new information. Mulford and Robinson (2002) also address this problem, stating: Alternative conceptions play a larger role in learning chemistry than simply producing inadequate explanations to questions. Students either consciously or subconsciously construct their concepts as explanations for the behavior, properties or theories they experience. They believe most of these explanations are correct because these explanations make sense in terms of their understanding of the behavior of the world around them. Consequently if students encounter new information that contradicts their alternative conceptions it may be difficult for them to accept the new information because it seems wrong...If anomalous new information is presented in a learning situation where the student is rewarded (with grades) for remembering it, the information may be memorized in order to earn the reward, but it is likely to be quickly forgotten because it does not make sense.

In our reading, we looked for specific misconceptions that our students might hold in the atomic theory or following units. The University of Dallas's Comprehensive Conceptual 
Curriculum for Physics describes the following misconceptions which students may have in atomic structure:

- There is only one correct model of the atom.

- Electrons in an atom orbit nuclei like planets orbit the sun. Electron clouds are pictures of orbits.

- Electrons can be in any orbit they wish. Hydrogen is a typical atom.

- The wave function describes the trajectory of an electron. Electrons are physically larger than protons.

- Electrons and protons are the only fundamental particles. Physicists currently have the "right" model of the atom. Atoms can disappear (decay) (Olenick)

In addition, a common error that students make is "...the easily avoidable one of not counting the correct number of electrons (equal to the atomic number for a neutral atom). They also fail to take into account the loss or gain of electrons if the subject species is an ion" (Miller). Other common misconceptions we identified in our reading were "Atoms are like cells with a membrane and nucleus, "The size of an atom depends on the number of protons it has," and "Hydrogen is a typical atom" (Horton, 2004).

\section{Research plan for the study}

This study was conducted at Kalamazoo Central High School and Loy Norrix High School in Kalamazoo, Michigan. The courses investigated were Chemistry and Honors Chemistry with students in grades 10-12. We read articles on the topics of common misconceptions in chemistry and identified common misconceptions about atomic structure. We did not find 
literature about the use of learning stations in high school science classrooms. The use of learning stations in elementary classrooms appears to be more common.

We designed the learning station activities so that three of the stations would identify students who have these common misconceptions. At the stations, we planned to assess whether students have these misconceptions by observing them completing activities and through their writing at stations. We planned to set up between four and eight stations throughout the classroom. Students would receive a station guide and would have about have about ten minutes at each station to complete the activity. Teachers would address any misconceptions observed by immediately by talking to students at a station. We collected samples of students' warm up questions, station guides, quizzes and chapter tests including items assessing those specific misconceptions we observed. Examples of these test items can be viewed in the following section.

\section{Analysis and Interpretation}

In our reading we identified several common misconceptions that were relevant to our teaching in this unit. Of those common misconceptions in the literature, we noticed some overlap with misconceptions we observed in our classes. The chart below notes student misconceptions we noted in the classes as well as how they were identified and addressed. These misconceptions primarily consist of chapter four content surrounding atomic theory and the scientists who contributed to it. 


\begin{tabular}{|c|c|c|c|c|}
\hline $\begin{array}{l}\text { Source } \\
\text { Chapter }\end{array}$ & Misconceptions & $\begin{array}{l}\text { How it was } \\
\text { identified }\end{array}$ & $\begin{array}{c}\text { Teacher follow up to address } \\
\text { misconception }\end{array}$ & $\begin{array}{l}\text { How } \\
\text { students } \\
\text { were } \\
\text { assessed }\end{array}$ \\
\hline Chapter 2 & $\begin{array}{l}\text { Dissolve is a Chemical } \\
\text { Change }\end{array}$ & $\begin{array}{l}\text { Noticed } \\
\text { during an } \\
\text { activity }\end{array}$ & $\begin{array}{l}\text { Immediate feedback during } \\
\text { stations } \\
\text { PowerPoint slide with correct } \\
\text { definition in lecture } \\
\text { John Collins writing prompt }\end{array}$ & $\begin{array}{l}\text { Question } \\
\text { and \% of } \\
\text { Students } \\
\text { Correct }\end{array}$ \\
\hline Chapter 4 & $\begin{array}{l}\text { "JJ Thomson's } \\
\text { contribution was the } \\
\text { Plum Pudding Model" }\end{array}$ & $\begin{array}{l}\text { Warm Up - } \\
\text { John Collins } \\
\text { Type } 2 \text { writing }\end{array}$ & $\begin{array}{l}\text { Discussed in following classes } \\
\text { and next day in first class }\end{array}$ & \begin{tabular}{|l} 
Essay \\
question on \\
Chapter 4 \\
Test
\end{tabular} \\
\hline \begin{tabular}{|l} 
Chapter 4 \\
$(10 / 3 / 13)$
\end{tabular} & $\begin{array}{l}\text { "Atomic Mass" as a } \\
\text { part of the chart }\end{array}$ & $\begin{array}{l}\text { Overheard } \\
\text { students } \\
\text { discussing it }\end{array}$ & $\begin{array}{l}\text { Announced to class that there } \\
\text { is no such thing as "atomic } \\
\text { mass" at this point. It's atomic } \\
\text { number and mass number }\end{array}$ & \begin{tabular}{|l} 
Chapter 4 \\
Test - Chart \\
on first page
\end{tabular} \\
\hline $\begin{array}{l}\text { Chapter } 4 \\
(10 / 8 / 13)\end{array}$ & $\begin{array}{l}\text { Rutherford's } \\
\text { contribution was the } \\
\text { gold-foil experiment and } \\
\text { he discovered the } \\
\text { nucleus... (missing the } \\
\text { HOW part, need more } \\
\text { information) }\end{array}$ & $\begin{array}{l}\text { Warm Up - } \\
\text { John Collins } \\
\text { type } 2 \text { writing }\end{array}$ & $\begin{array}{l}\text { Discussed in following class } \\
\text { and next day in first class }\end{array}$ & \begin{tabular}{|l} 
Essay \\
question on \\
Chapter 4 \\
Test
\end{tabular} \\
\hline Chapter 4 & $\begin{array}{l}\text { Rutherford only } \\
\text { discovered the nucleus }\end{array}$ & $\begin{array}{l}\text { Warm Up - } \\
\text { John Collins } \\
\text { type } 2 \text { writing }\end{array}$ & $\begin{array}{l}\text { Discussed in following class } \\
\text { and next day in first class }\end{array}$ & Test \\
\hline Chapter 4 & $\begin{array}{l}\text { Neutrons make atoms } \\
\text { electrically neutral }\end{array}$ & $\begin{array}{l}\text { Practice } \\
\text { worksheet }\end{array}$ & $\begin{array}{l}\text { Discuss in notes, warm ups, on } \\
\text { quiz, on essay question on test }\end{array}$ & $\begin{array}{l}\text { Quiz and } \\
\text { test essay } \\
\text { question }\end{array}$ \\
\hline Chapter 4 & $\begin{array}{l}\text { There is only one model } \\
\text { of an atom (usually Bohr } \\
\text { model) }\end{array}$ & $\begin{array}{l}\text { Observation, } \\
\text { during lecture }\end{array}$ & $\begin{array}{l}\text { PowerPoint to address more } \\
\text { current models of the atom }\end{array}$ & Warm Up \\
\hline
\end{tabular}


We focused on two particular misconceptions through the methods listed in the chart. Multiple students in both schools held misconceptions about the contributions of Ernest Rutherford and J.J. Thomson to atomic structure. We wanted students to understand on a basic level the relationship between these scientists' investigations and their conclusions about the atom: that Rutherford concluded that the atom contained a positively charged nucleus and was mostly empty space and that Thomson discovered the electron using the cathode ray tube and developed the plum pudding model of the atom. We first examined students' prior knowledge with the pretest prompts "Explain J.J. Thomson's model of the atom" and "Explain Rutherford's model of the atom". Below is a sampling of student responses.

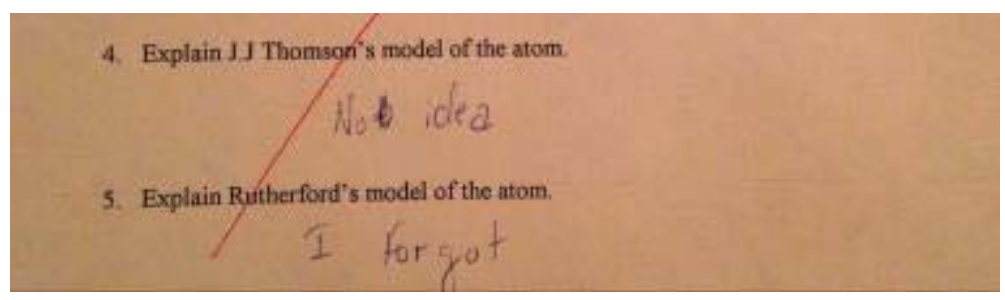

Image 1 - student pretest: student did not know any of the answers.

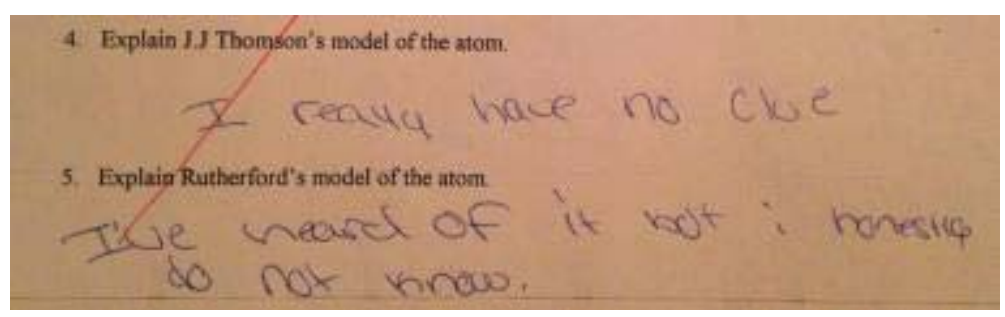

Image 2 - student pretest: student did not know any of the answers but said they have heard of Rutherford's model.

After the pretest, the scientists' contributions to the corresponding atomic models were taught through direct instruction with PowerPoint slide images, student notes taken from the textbook, small group research summarized in a poster, and peer presentations of the posters. 
After these activities, students were given a warm up question on a subsequent day using the same prompts from the pretests to determine their understanding.

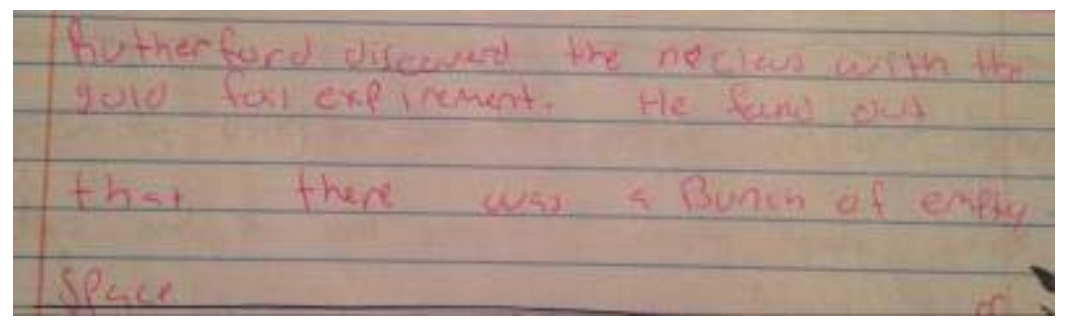

Image 3 - student warm up: This student was missing the "how" part of Rutherford's contribution. He/she also didn't describe the experiment.

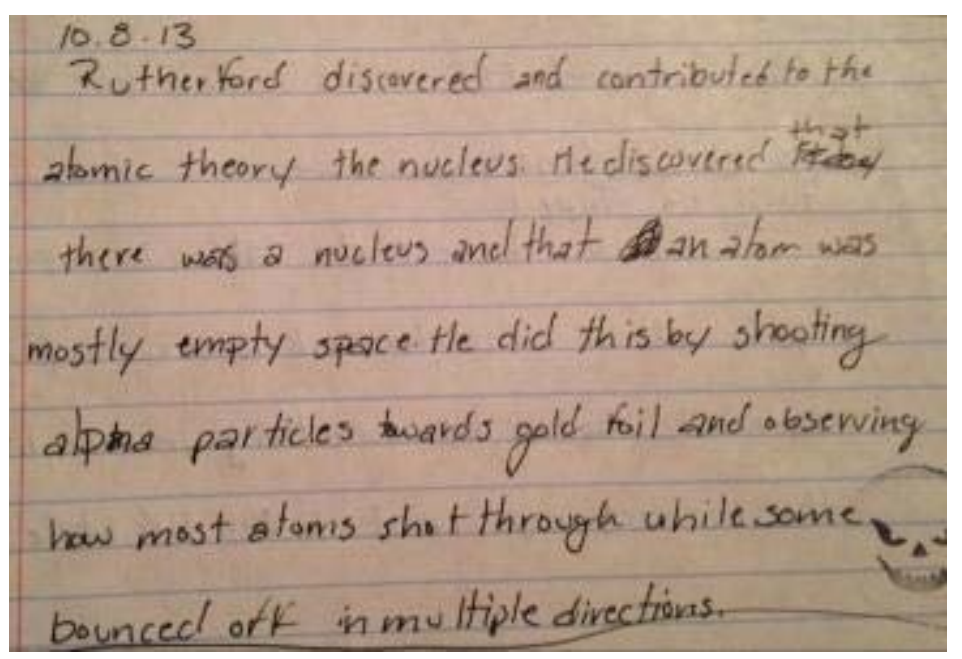

Image 4 - student warm up: This student had a great grasp of Rutherford's contribution to the atomic theory and included all of the components we were looking for in this prompt.

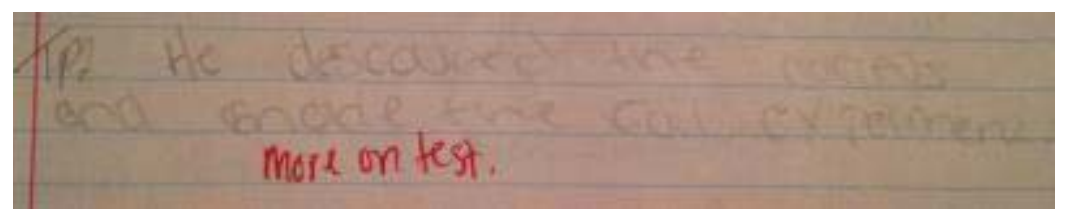

Image 5 - student warm up: This student understood the basics of Rutherford's model ("He discovered the nucleus"), however was missing the key components of the "how" and the concept of empty space. 


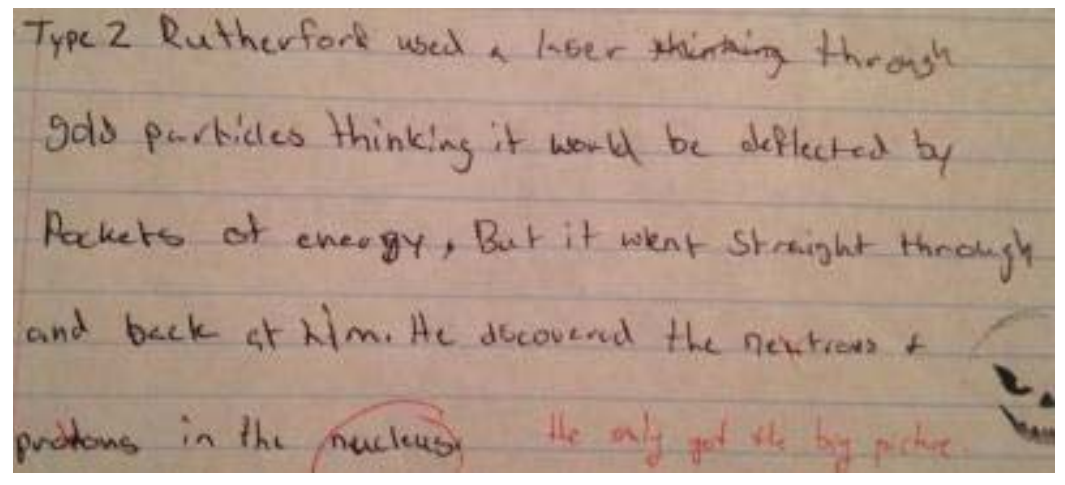

Image 6 - student warm up: Student was missing some details about empty space and added some incorrect information about Rutherford's discovery.

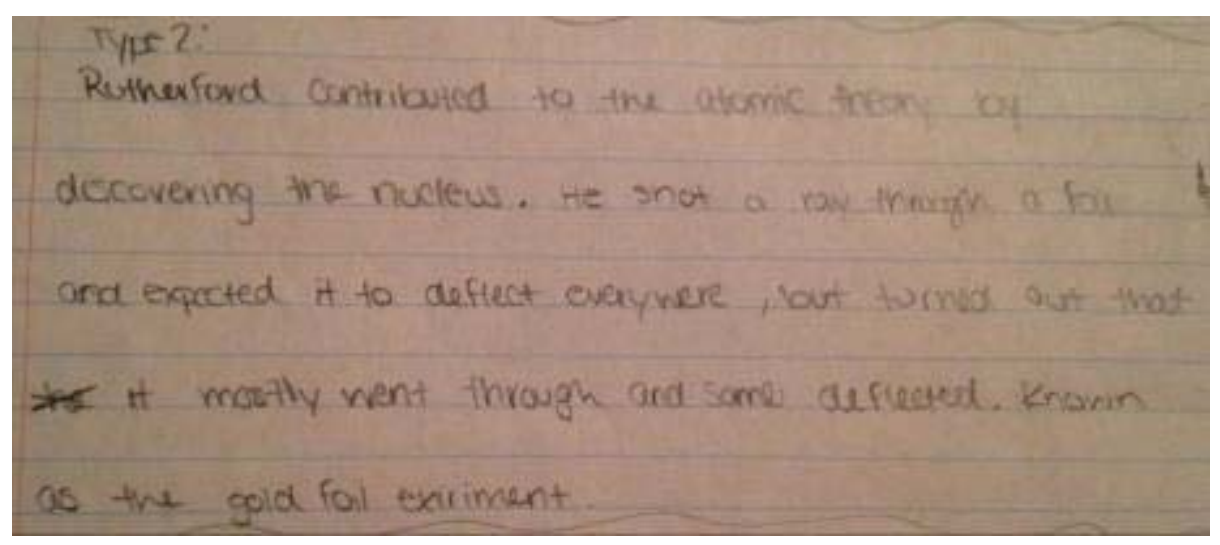

Image 7 - student warm up: Student was missing the idea that Rutherford contributed to the idea that atoms are mostly empty space.

As a final review before the unit assessment, students performed the stations activity. We wanted to see if the interventions and practice we had provided changed or strengthened students' understanding of atomic models. For consistency, the questions were phrased the same way: "Explain J.J. Thomson's model of the atom" and "Explain Rutherford's model of the atom". 


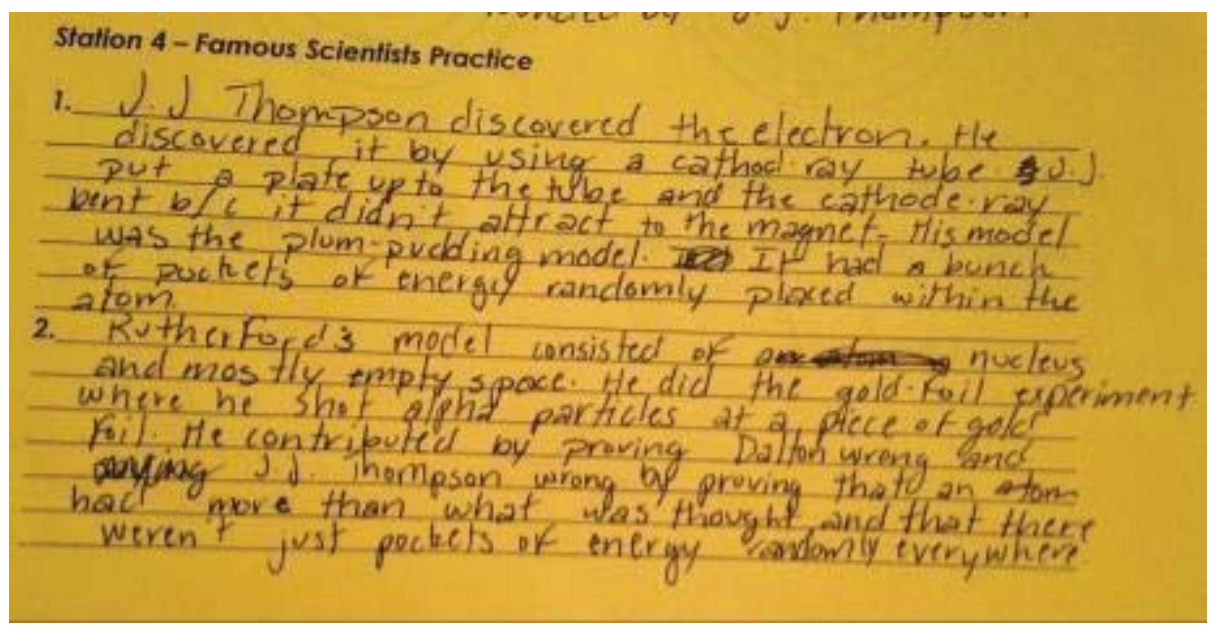

Image 8 - student station guide: thorough answers made for both questions by student.

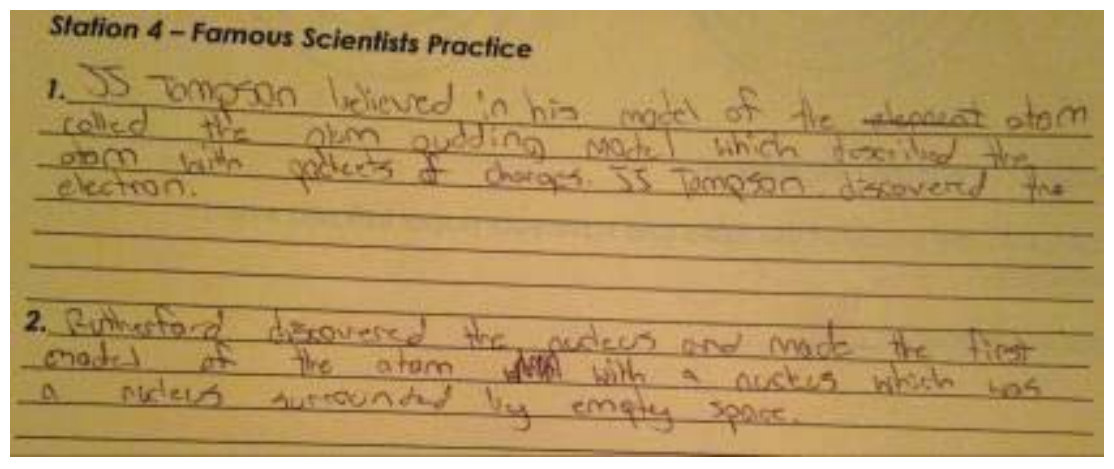

Image 9 - student station guide: student did not describe how both J.J. Thomson and Rutherford made their discoveries.

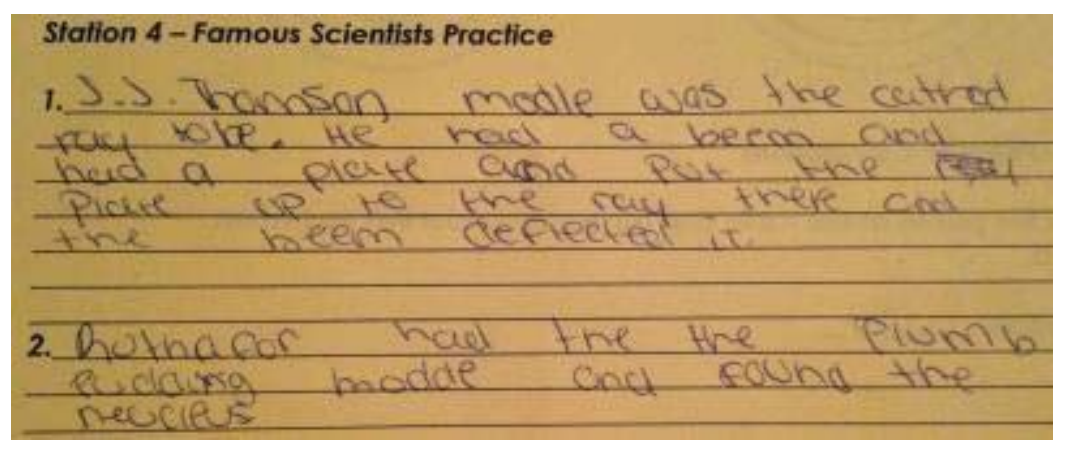

Image 10 - student station guide: student described Thomson's experiment, but failed to mention what he actually discovered. Student stated that Rutherford had the plum pudding model and lacked details about Rutherford's experiment or model. 
Another persistent misconception that we noticed was not addressed in the stations activity but was taught using other strategies. This misconception is that an atom is electrically neutral because of neutrons (arising because the words are similar). This concept was taught first in a lecture. The students learned that in a neutral atom the number of electrons is equal to the number of protons, therefore the negative charges cancel out the positive charges. The concept was revisited several times in an inquiry activity, an atoms practice sheet, and a quiz before the students took the unit assessment. Below are samples of student work which show a range of answers on the atoms practice sheet and the atoms quiz.

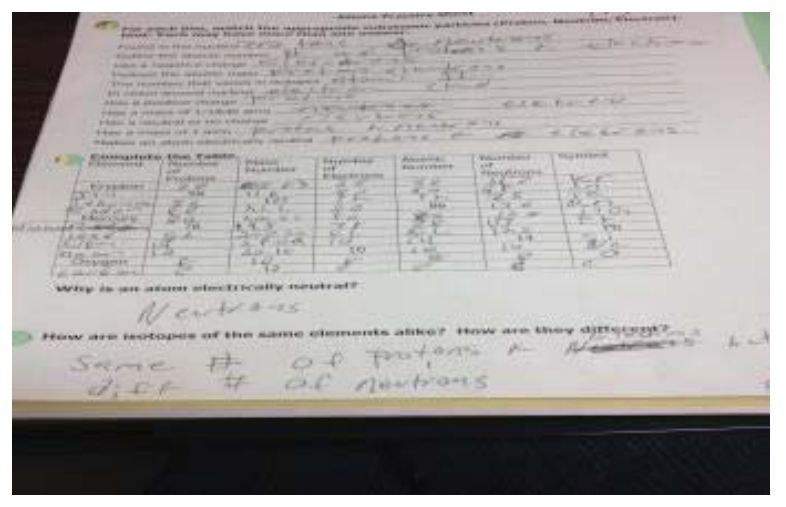

Image 11: student incorrectly answered the question "Why is an atom electrically neutral?" with "Neutrons" on the atoms practice sheet.

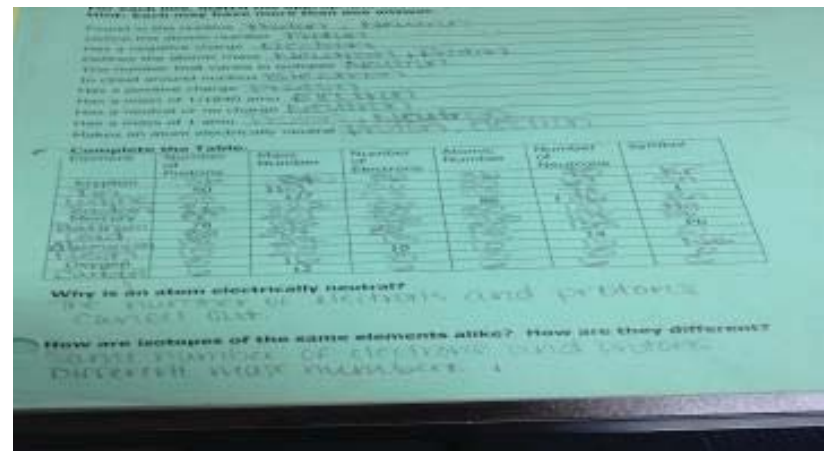

Image 12: student correctly identified question "Why is an atom electrically neutral?" on the practice sheet with "The number of electrons and protons cancel out." 


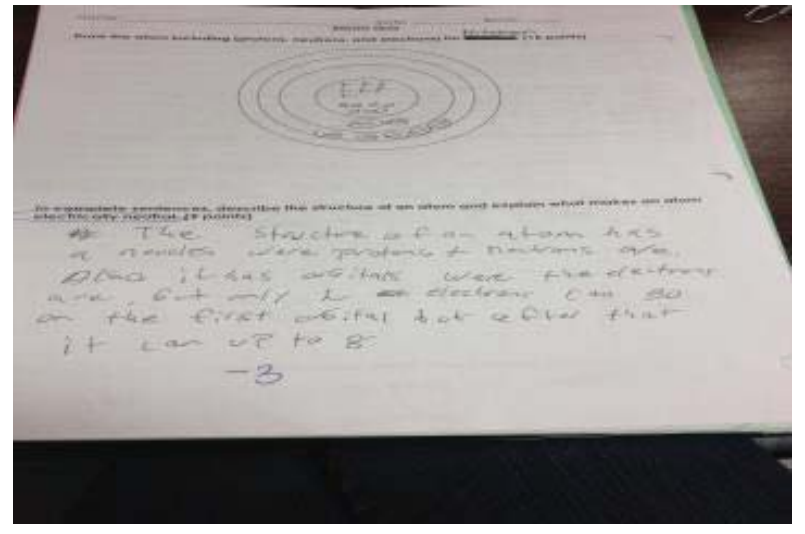

Image 13: for the quiz question "Describe the structure of an atom and explain why an atom is electrically neutral" student only describes the structure and omits describing why it is electrically neutral.

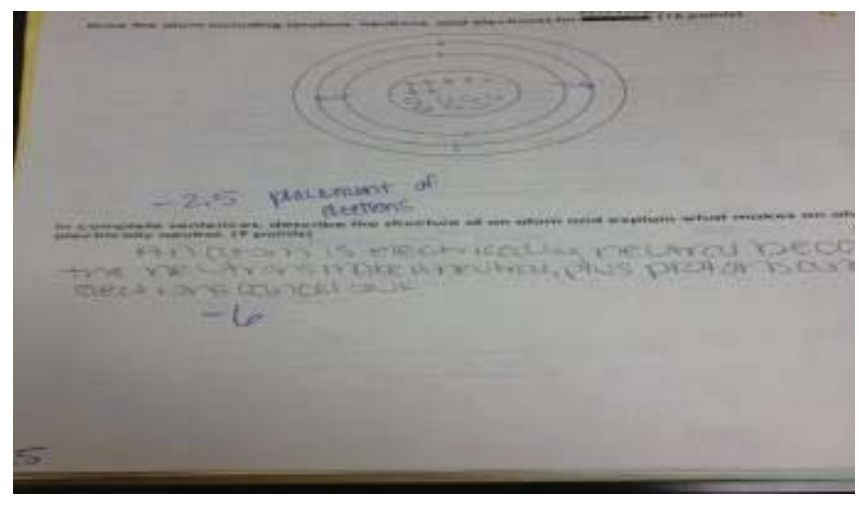

Image 14: student incorrectly answers "An atom is electrically neutral because the neutrons make it neutral, plus protons and electrons cancel out" on the quiz.

\section{Discussion}

Elementary classrooms often use stations, or centers, as an effective learning strategy and we were also able to see success with this strategy in our secondary classrooms. We observed that stations provided an opportunity to meet diverse student needs in several ways. For one, they provided all students an opportunity to get more individualized support because the teachers circulated among the stations. One teacher was able to listen to, discuss, and reteach a group of 
three to four students on a chunk of content that was previously taught. We observed more student discussion because students were standing together at the same station instead of at their individual desks. Also, the stations provided a visual and often hands-on activity to help strengthen understanding. Additionally, the activity provided an alternative to a worksheet, where the student's focus was on practicing one key concept, with fewer questions and lots of teacher support. In the stations format we were able to check-in with our special education students without singling them out in a whole-group setting.

Kari and Claudia have often used stations to go beyond the initial lecture and practice, in order to further the students' understanding and review for assessments. They have used matching models, Venn diagrams, computer animations, and other manipulatives in particular stations. Kari found that matching models allowed students to quickly categorize content. This type of station allowed her to quickly assess student understanding and what needed to be retaught. Also, these stations forced students to get their work checked and initialed by the teacher, providing an opportunity for Kari to collect informal data and reteach on the spot. Claudia found that the use of stations as a review activity has increased time on task for her students. Kids who usually would wait to do a worksheet or other review work at home or choose not to complete it at all, were required to get the work done in class. This allowed Claudia to make observations and determine which topics needed more time and practice in the future. Additionally, students who would normally have incomplete or missing work were completing the work in class. Claudia was also able to address students' misconceptions or incorrect answers immediately to steer them in the right direction for the future assessment. For teachers it provided a quick informal check on student understanding. While we might not be able to tell if the student conceptions have changed because of that station activity, we can see if they are learning or strengthening their understanding. 
In student evaluations, we found the students sometimes disliked the idea of stations (primarily because we force them to get up and move around) but also stated that stations were instrumental in developing understandings in each unit of study. Students report that they like the student-to-teacher ratio during stations, where the teacher is circulating and readily available to provide support.

Kalamazoo Public Schools requires the use of common growth assessments as part of annual teacher evaluations. By using several different learning strategies and formative assessments, including stations, we were able to use the observational data we collected as part of our evaluation. In our opinion, data from district level assessments alone was not reflective of what occurred in our classrooms. As teachers, we are allowed to provide additional evidence of student learning, when or if the district data is not reflective of the required student improvement. The data we collected helped support our teaching methodologies and effectiveness.

Through this study we made many observations about the utility of stations as a strategy in our classrooms, but did not determine whether the stations led to conceptual change for students who came into the unit with incorrect preconceptions or developed misconceptions during the unit. As we collected data we did not link it to individual students so we did not know which students had misconceptions and if they were corrected through the use of stations, through the use of other strategies, or not corrected.

\section{Conclusion}

In this study we learned about student misconceptions in atomic theory and structure in the literature and in our classes. Our list of misconceptions in this unit was different from the ones present in the literature because we focused only on atomic structure and asked specifically about 
theorists and their contributions. Our students shared a misconception identified in our readings as common: "there is only one correct model of the atom."

We also determined that more research needs to be done to conclusively determine if the misconceptions were corrected during stations activities. The pretest format we used could work well, but specific questions would need to be modified in order to make the connection between the pre and post test data. Many students know that the pretest is not connected with a grade, therefore do not take them seriously. Most students put their name on it and turn it in completely blank or randomly answer questions. This could skew our results greatly.

The structure of the stations allowed us to easily assess the students' understanding, but because of the teacher to student ratio (both Kari and Claudia had over 25 students in each class), we couldn't assess and address every student at every station. Other teachers might find it useful to integrate stations into their classrooms because it is a great alternative to worksheets. It addresses the kinesthetic learning style and encourages student movement and discussion during class. It allows teachers to circulate so students can have one on one interaction when possible. It is especially beneficial in co-taught classes where there is more than one adult in the room. It reduces the number of questions that a student needs to complete and gives them a concrete time frame for each station. The ability to move on after a given time frame regardless of station completion is acceptable as long as the student is engaged at each station. For teachers, this is an easy way to modify and differentiate the activity for learners with different ability levels.

All teachers could also benefit from being aware of their students' common misconceptions. Knowing these misconceptions give teachers the opportunity to address them multiple times in the classroom in different ways. Misconceptions are commonplace in the science classroom and often times remain misconceptions forever if not addressed properly. Initially we planned to study the question "How will the use of station activities affect student misconceptions in the atomic structure unit?" However, when we looked at the data we 
were able to collect during this unit, we decided to change our question to "What will happen if we try to use station activities to address student misconceptions in atomic structure?" We made this adjustment because we thought to answer the first question thoroughly and conclude that the intervention of station activities affected student misconceptions we would need pre and post tests and a control group. We were not able to do that in this time period but it would be a possible second stage for this action research.

\section{Future Study}

We found this project to be a good initial investigation that could lead to future research into misconceptions in high school chemistry. If we continued with this second stage, we could develop longer, more detailed, pre-tests for each class based on the ones given by Claudia in this unit. This would require us to motivate the students to take the pretest more seriously and to answer the pretest items more completely. Then, we would give the same or very similar items as a post test and compare student scores. The disadvantage of this design would be that it is difficult to determine the misconceptions that cause students to answer pre or post test items incorrectly.

Another possibility we considered would be to try two different interventions to address student misconceptions. For example, one class could use the station activities we used this time. Another class could complete a worksheet or book questions addressing the same topic. This would allow us to have a control group and to compare these two interventions to see whether the station activity was more effective. The disadvantage in this case is that we think all of the strategies we use currently such as stations, labs, warm-ups, worksheets and manipulatives are beneficial to students and we don't want to omit these for any group of our students.

Instead of using the control group design we would prioritize an investigation design that could be more easily integrated with our teaching practice. We would like to continue our 
investigation of misconceptions by taking a closer look at the type of misconceptions our students have. We would not focus only on station activities but instead look at the impact of all of our teaching strategies during a unit. We would also like to track the conceptual development of individual students. In this investigation we observed that some of the students have misconceptions that they have developed prior to the class and some misconceptions are developed during the class. In other cases, the student does not have a misconception, but rather an incomplete recall of a topic. We could categorize these errors and develop a checklist that we would use with students as we observe them and assess their work. This would help us understand which misconceptions are most prevalent and to more rigorously track which students have these misconceptions. Kari would like to try a keeping a chart of all of her students with common errors listed. When she observes a common error, she would check this box by the student's name. For example, she has observed that students think that neutrons make atoms electrically neutral. So, any time she hears or observes a student making this error she will note it in her chart. With this data, she would be able to see which students corrected this misconception by the end of the unit as shown on the unit exam. We would also like to increase our focus in our readings and study design on which strategies are most helpful for changing students' particular misconceptions. 


\section{Contributions to the Action Research Project}

Claudia Witt - administered stations, collected data, analyzed misconceptions, collaborated on writing paper

Rebecca Joyce - researched readings, summarized readings, observed stations in Claudia's class, collaborated on writing paper

Kari Luckett - administered stations, collected data, analyzed misconceptions, collaborated on writing paper 


\section{Chapter 2}

\section{The Impacts of MiTEP on My Career in Education}

In 2011, my department head shared an opportunity to earn credits towards a Master's degree through Michigan Technological University while partnering with them to research and promote earth science education in Kalamazoo Public Schools. The partnership was designed to increase teacher knowledge and experiences in earth science that could then be implemented in any middle school or high school science classroom. I was eager to sign up but was getting ready to have my second child, so when they added a fourth year to the program and a second year to the partnership with Kalamazoo Public Schools, I jumped at the opportunity. After school ended in 2012, I traveled to the Upper Peninsula to start my adventure at Michigan Technological University in the earth systems institute course.

The summer institutes consisted of one week on campus at Michigan Technological University and one week on campus at Western Michigan University in Kalamazoo, Michigan or Jackson Community College in Jackson, MI. Our main instructor, Bill Rose, was assisted by several graduate students to make sure we learned a lot, ate well and saw the most we could see while in the Upper Peninsula. As a science teacher, I have always loved to visit scientifically significant areas, but to see these areas with resident experts made the experience priceless.

The first summer we visited stromatolites. These are some of the oldest known organisms on earth at three and a half billion years old. This was also the location where we did our first earth cache. An earth cache is a scientifically significant area that you find using a GPS. When you find the location you answer questions provided by the author of the earth cache to mark you entry as a success. We learned how to enter GPS coordinates and perform a trek to find an earth cache site. This would become important because later in the week when we would each make our own earth cache in geo-relevant areas of downtown Houghton. My earth cache in 
Houghton was about a lava flow that flowed through downtown Houghton, ultimately determining where houses could be built in present day. This earth cache concept, not content, was more important to me. We were responsible for researching, and, more importantly, developing the background information, pictures and questions for visitors to our earth cache. Developing an earth cache, gave me an opportunity to develop a type of virtual lesson plan I had never created before. This activity will be available for hundreds of visitors in the future to visit. I went on to develop an earth cache lesson plan for an enrichment program for English language learners during summer school of their eighth grade year. The earth cache experience allowed me to create unique opportunities for these students that connected content and the use of technology.

Our visit to the stamp sands was particularly of interest to me. The stamp sands were beach areas that had demonstrated longshore drift of waste from the mines. When mining was active there was a large grinding machine that took all of the waste rock and ground it up and disposed of it out into Lake Superior. This waste had arsenic and other trace metals in it. While it has been determined that this is not a threat to human health, it has dramatically affected property values at the beach. On one side of the pier there was a black stamp sand beach and on the other side was the pristine sand we normally find on Lake Superior shorelines. As a teacher of environmental science, this was a real life example of the human impact on our planet. It also provided me with a debatable issue that my students could use the environmental decision making model to determine what remediation should be done.

Also in Earth Systems Institute I we learned how to take the strike and dip of rocks, visited potholes formed by a waterfall, and visited a river, deemed "Shopping Cart River," based on its location near the expansion and development of a local Walmart. We also learned the history behind mining at the Quincy copper mine with a tour of the museum and the mine from Bob Barren. We saw what a classroom looked like in the mine - dark, dingy, and tiny! There 
were so many areas near Michigan Technological University that could serve as outdoor classrooms, I left the Upper Peninsula excited to see what was available near my school. In the second half of Earth Systems Institute I, we traveled around the southwest corner of Michigan from Kalamazoo's Woods Lake to Grand Ledge to the eskers near Jackson, exploring the impact glaciers left on our state. We visited the Western Michigan University Michigan Basin Core Research Laboratory, which is a hidden gem for Western Michigan University and Kalamazoo. This site has core samples from all of Michigan that can serve as important teaching tools for students. We were able to contribute what would be useful to classroom teachers in the development of the CoreKids program. In this program, graduate students bring core samples into K-12 classrooms. Woods lake is a pothole lake located in a residentially developed area of Kalamazoo. This lake has frequent water quality testing done from students at Western Michigan University area. Due to the shape of a pothole, the houses on the edge of it provide a great deal of runoff into the lake. This and the runoff from the roads pollutes the lake. Also, the lake is frequented by ducks and other waterfowl, which cause e.coli levels to be too high for swimmers to enjoy the area. This lake is also visited by many inner city children because of its closeness to highly populated areas, as well as being on the city bus line. The water quality testing we were able to do on this lake provided me with access to real time data in my local community. For environmental science classes this was a great example of urbanization and how pollution affects freshwater supplies. It also allowed me to talk to my classes about springfed lakes in the area, which I was previously unaware of.

Earth Systems Institute II in the summer 2013 also provided many authentic learning experiences. My favorite activity both summers was mining for copper. The rock samples I collected sit on the demo table in my classroom and have served as conversation starters with many of my students. We also continued doing water quality testing, visited an EPA site on the Kalamazoo River, and spoke with one of the rescuers of turtles after the Enbridge oil spill in 
Marshall, MI. With the extensive coverage of water quality testing and these additional experiences, I became eager to implement this in my own classroom, but I was no longer teaching environmental science. A colleague, also in the MiTEP program, and I developed a water quality testing project for our AP Chemistry courses. This project would never have come to fruition without the exposure and practice we received over the summer institutes and the networking it required with other teachers in my district. We also went on two tours of water treatment plants and were able to compare the process in a smaller Upper Peninsula town to that in a more urban Lower Peninsula city. I was never aware how much Chemistry was present in this process. This is a tour I would like to schedule for my chemistry classes in Kalamazoo, again trying to show them the real-life applications of Chemistry.

I took three science content courses while in the MiTEP program. These classes developed and strengthened my content knowledge, even though I have a minor in earth science Much of this material was not new for me but instead was more of a refresher.. I developed a study group with two fellow teachers from Kalamazoo Public Schools and we met about once a week during each semester. This time allowed me to teach the others, who had little to no postsecondary earth science education, which strengthened my own understandings. It also allowed us time to talk about our current teaching practices, brainstorm ideas and develop strong friendships. The one criticism I had with these classes was that I was concise in my answers because I had content knowledge. I didn't feel the need to become too wordy in my answers, which caused me to be marked down in my grade. I thought it was unfortunate that I needed to provide all sorts of extra details indicating I did research to find an answer that I already knew the answer to.

In addition to science classes, we also took a STEM research class about inquiry-based learning. This class would have been a great class to take at the beginning of our program. However, we took this at the end of our program and we had covered inquiry extensively in our 
pedagogy workshops. However, having had previous interactions with the professor when at Michigan Technological University, I actively sought out an alternative assignment for the final paper that would be more beneficial for me and my school. I developed a professional development plan that could be implemented within my department meetings at school to teach others about all aspects about inquiry and its implementation. Since so many of my colleagues were involved in MiTEP, the program won't be useful right now but with a few retirements or teacher departures, this program could be used for new staff or as a refresher in a few years.

The Geology of National Parks course was my first field-based course. The trip was three weeks and consisted of reading and writing, as well as activities that applied our understandings. These experiences were similar to what I experienced in my science content courses through MiTEP. We were able to see parts of Colorado and Utah, which I had never visited before. Again, having experts on the area and the landforms, made this a truly once in a lifetime opportunity. Our instructors were patient, having students with varying levels of experience, and fair in their grading practices. They provided ideas on how to implement our findings into our classrooms regardless of whether we taught Math or Science. The final project was interesting because it encouraged the use of technology to apply something we learned during the course.

The lesson study and action research course provided me with experiences that allowed me to examine what I was teaching and the effectiveness of it My group chose to do action research with a qualitative focus on the teacher's learning experiences. We examined student misconceptions in Chemistry. It was interesting to design targeted learning experiences to address these misconceptions and see if our intervention helped resolve these preconceived ideas. What I learned from this experience is that I thought every activity I planned was to address some specific content understanding or apply knowledge but I never followed up to see if it was successful or not. This course helped me understand how to plan, implement and assess success in my classroom and then be able to adapt my lessons to continually increase the number of 
students making connections within the content. The lesson study also allowed me to choose something within my classroom to focus on. As teachers, we often write new lesson plans but struggle to follow up on the success of that lesson. This class provided me with the opportunity to work with another chemistry teacher at Loy Norrix High School. It was fun to have collaboration time with a teacher in my district but not at my school. We have continued and strengthened that relationship and still continue to meet for planning.

Throughout each of the first two years we attended regular pedagogy days. This was a time for us to get together as an entire cohort either in Kalamazoo or Jackson, MI. We would spend our days exploring inquiry, doing activities, planning lessons, and having time to work collectively. I looked forward to these days because over the summer you build strong relationships with your cohort members and when you go back to school it's hard to keep in touch. These days provided time for us to catch up and learn from each other. The pedagogy days focused on developing our skills in science content but also served as a break from our regular schedule. The also helped our cohort prepare for what we would do in each of the summer institutes and our final summer with the national park internship.

In the summer of 2014, as the last field experience in the MiTEP program, I performed a three-week internship at Pictured Rocks National Lakeshore in Munising, MI. This experience was truly the culmination of what I had learned while part of the MiTEP program. The content I gained in my summer institutes and earth science courses helped me understand the area scientifically. It built my confidence and strengthened my knowledge in earth science concepts that I previously thought I understand, having obtained a minor during my bachelors program. I was able to apply my knowledge which is what I always want my students to be able to do and this first-hand experience reminded me of the challenges and rewards it can bring. I was also able to work with colleagues that I had come to know personally and professionally over the last three 
years, which allowed for easy collaboration on our project. We knew what our strengths and weaknesses are and were able to capitalize on that during our time. This has encouraged me to make and maintain better working relationship with my department. I have done more common lesson planning at the building and the district level. Currently, I common plan for chemistry with a teacher in my building and for AP Chemistry with my counterpart at Loy Norrix High School.

The MiTEP program encouraged leadership opportunities for all of its cohorts. In my two years some of our pedagogy days we were spent with guest teachers from previous cohorts. We looked at different science concepts from fossils to astronomy. Since we were the last cohort we have been unable to do this for other groups but the confidence and presence the program has given us have been reflected in our districts. Since joining the program I have had the opportunity to host two Woodrow Wilson fellows from Western Michigan University. This has allowed me to show them how to implement inquiry based education, work with colleagues to common plan and use the people in your district who are experts. I hope that the networking I do, because of the MiTEP program, encourages them to do the same. I have also done professional development sessions within my district. More importantly, though, I learned how to present to my peers.

One of the requirements of the MiTEP program is to present in a lesson share-a-thon at MSTA. I took on a leadership role by developing the Powerpoint for my group. My group members sent me their information and I compiled and edited this into a presentation. This was an excellent experience and was the second time I had presented at MSTA since starting the MiTEP program. Teaching can be such an isolated field and having the time and opportunity to work with others, collaborating and networking, has been one of the best facets of the MiTEP experience. 
MiTEP also encouraged and passed along many grant writing opportunities. I applied for and received a grant from MSELA. The grant covered my expenses to attend NSTA in Boston, MA. My counterpart at Loy Norrix also received this grant and we were able to travel together. While there we attended Chemistry and AP Chemistry sessions, which we are both currently teaching. I learned some great new demos and lots of helpful information regarding the curriculum rewrite for AP Chemistry. This opportunity would never have been a possibility in my district with all of our budget cuts. MiTEP paid for our hotel and our admittance to the conference while we were there. We then helped a graduate student present a lesson on the Sudbury impact we had participated in during a pedagogy day. This was another chance for us to present to our peers and further develop our confidence and leadership experience.

Previous to my MiTEP experience, grant writing was intimidating, scary and time consuming process. Although I knew it would be worth the time and effort it was hard to get started. Having now received a grant, I feel much more confident in my grant writing abilities. Since receiving the MSELA grant, I applied for and received another grant from the American Chemical Society for Labquest PRO equipment for my Chemistry and AP chemistry classes.

In 2009 I received a Master's degree in educational leadership from Western Michigan University. With the hopes of one day moving into a curriculum director position, I knew that it was important to have a degree in both leadership and science content. The science education degree from Michigan Technological University, supported through the MiTEP program, will provide that link for a future career. In the meantime, however, I am enjoying incorporating more inquiry-based lessons, collecting my own classroom data and mentoring future teachers in my own classroom. I have better relationships with my fellow MiTEP staff members and connections across the middle schools that feed to my building. While our district doesn't provide time for vertical alignment in our professional development, the time we spent in MiTEP allowed us to evaluate the current curriculum at each level. As teacher leaders, most of us work 
on curriculum writing in the summer and we will be instrumental in improving the content and the delivery of science education in all science classrooms across the district. 


\section{References}

Barke, H., Hazari, A., \& Yitbarek, S. (2010).Misconceptions in chemistry: Addressing perceptions in chemical education. Berlin: Springer-Verlag.

Committee on Development of an Addendum to the National Science Education Standards on Scientific Inquiry, Center for Science, Mathematics and Engineering Education, National Research Council (2000). Inquiry and the National Science Education Standards: A guide for teaching and learning. Washington, D.C: National Academy Press.

Eisenkraft, A. (2003). Expanding the 5E model. The Science Teacher, 56-59

Golub, J. (2014) Study: poverty risk factors affect school performance. The Daily Pennsylvanian. Retrieved from http://www.thedp.com/article/2014/02/gse-education-study-poverty-riskfactors.

Horton, C. (2004). Student alternative conceptions in chemistry. Retrieved from http://www.daisley.net/hellevator/misconceptions/misconceptions.pdf

Kier, M.W., Blanchard, M.R., Osborne, J.W., Albert J.L. (2014). The Development of the STEM Career Interest Survey (STEM-CIS). Research in Science Education. 44, 461-481.

Kind, V. (2004). Beyond appearances: Students' misconceptions about basic chemical ideas 2nd edition. Retrieved from http://www.rsc.org/images/Misconceptions_update_tcm18-188603.pdf 
Mack, J. (2013) Nearly half of Kalamazoo-area public schools students participating insubsidized lunch program. Kalamazoo Gazette. Retrieved from http://www.mlive.com/news/kalamazoo/index.ssf/2013/01/44_percent_of_kalamazooarea_p.html.

Michigan teacher excellence program Michigan teacher excellence program (MITEP): A model for improving earth science education nationwide. (n.d.). Retrieved from http://mitep.mspnet.org/.

Miller, G. (n.d.). Misconceptions and issues in quantum theory. Retrieved from http://apcentral.collegeboard.com/apc/members/courses/teachers_corner/155004.html

Mulford, D. R., \& Robinson,W. R. (2002), An inventory for alternate conceptions among first semester general chemistry students. Journal of Chemical Education 79 (6), 739-744.

The Next Generation Science Standards (2013) Retrieved April 15, 2014 from http://www.nextgenscience.org/next-generation-science-standards.

Olenick, R. P. (n.d.). Helping students learn physics better preconceptions and misconceptions. The Comprehensive Conceptual Curriculum for Physics (C3P) Project. Retrieved from http://phys.udallas.edu/C3P/Preconceptions.

Volkmann, M.J., Abell, S.K. (2003). Rethinking laboratories: tools for converting cookbook labs into inquiry. The Science Teacher, 38-41. 